\title{
Analysis of the Effect of Nd:YAG Laser Irradiation on Soft Tissues of the Oral Cavity in Different Modes in an In Vivo Experiment
}

\author{
Renat Garipov ${ }^{1(\mathbb{D})}$, Morozova Elena ${ }^{1 \mathbb{D}}$, Ekaterina Diachkova ${ }^{1, *(\mathbb{D})}$, Albert Davtyan ${ }^{1 \mathbb{D}}$, Daniella Me- \\ likhova ${ }^{1}$ (D), Aygul Kazimzade E. ${ }^{1}$ (D), Svetlana Tarasenko ${ }^{1}$ (D) \\ 1 Department of Oral Surgery, E.V. Borovsky Institute of Dentistry of I.M. Sechenov First Moscow State Medical Univer- \\ sity (Sechenov University), Russian Federation, Moscow; renatius88@mail.ru (R.G.); lemua@yandex.ru (M.E.); \\ secu2003@mail.ru (E.D.); vantady@yandex.ru (A.D.); daniellochka2000@mail.ru (D.M.); ayqul.96@mail.ru, (A.K.); \\ prof_tarasenko@rambler.ru (S.T.); \\ * Correspondence: secu2003@mail.ru (E.D.);
}

Scopus Author ID 57200189811

Received: 6.06.2021; Revised: 10.07.2021; Accepted: 15.07.2021; Published: 8.08.2021

\begin{abstract}
The development of laser medicine has led to its use in dentistry further to improve existing treatment methods, including surgical techniques. The variety of lasers allows them to be used for procedures on the soft and bone tissues of the oral cavity as well as on the tissues of the teeth. The short duration of laser pulse action on tissues, selective action on pathological tissues in a sterile surgical field, and activation of local and humoral immunity of the oral cavity provides an increase in the regeneration potential of tissues of the postoperative area, which contributes to the shortening of wound process phases, favorable course of the postoperative period, and shortening of the healing time. Our article presents the experience of using the Nd:YAG laser in different modes in replicating the effect of curettage of periodontal pockets in an experiment on laboratory animals. According to the study results, there was a difference in the healing time of soft tissues after their exposure to several modes of the Nd:YAG laser, which makes it possible to recommend each of them for individual clinical cases.
\end{abstract}

Keywords: Nd:YAG; neodymium laser; experiment; animals; periodontal pocket.

(C) 2021 by the authors. This article is an open-access article distributed under the terms and conditions of the Creative Commons Attribution (CC BY) license (https://creativecommons.org/licenses/by/4.0/).

\section{Introduction}

The surgical phase in treating patients with inflammatory periodontal diseases has been widely described in the literature [1-3]. Different classifications of treatment methods have been proposed [4]. For this purpose, special cutting and rotary instruments are successfully used. However, the difficulties in performing surgical manipulations lie in the conditions of difficult visibility of the surgical field due to bleeding, apparent postoperative edema, pain syndrome, a long healing time of soft tissues, a decrease in the volume of dental tissues when exposed to mechanical instruments, and the possibility of formation of coarse scars [5].

For these reasons, it seems promising to replace cutting and rotary instruments with laser technology.

For several decades, various physicians have actively used lasers in daily medical practice, including dentists. Despite their widespread use, the indications for working with them in the periodontal field are limited.

Currently, diode, erbium, Er:YAG, and Er:YSGG lasers are most commonly used in dentistry for soft tissue processing [6-11]. The Nd:YAG laser is one of the newest lasers used https://biointerfaceresearch.com/ 
in dentistry because its improvement has reduced the penetration depth of pathological tissues and the impact on unmodified tissues. Since the main chromatophores for the Nd:YAG laser radiation are water and hemoglobin, its use is very relevant when acting on pathological periodontal tissues.

Impulses of equal energy, depending on duration, produce unequal effects on the target tissue. Consequently, when changing time from one pulse to another at the same energy level, different effects are obtained: pure ablation, ablation with coagulation, and coagulation without destroying soft tissue. Thus, by choosing the parameters of duration, strength, and frequency of the pulse sequence, an individual mode of action is selected for each type of tissue and pathology. This makes it possible to exclude burns of the surrounding tissue. The laser radiation contributes to the eradication of pathogenic microflora. The absence of direct contact of the instrument with the tissue during a surgical procedure eliminates the probability of additional infection [12-14].

Our study aimed to determine the effect of Nd:YAG laser irradiation on the healing process of periodontal tissue in laboratory animals after periodontal pocket curettage-type surgery.

\section{Materials and Methods}

For the experimental study, 20 male chinchilla rabbits weighing 2.5 to $4.0 \mathrm{~kg}$ were used, which were kept in a vivarium according to the rules of laboratory practice in preclinical studies in the Russian Federation (GOST R50258-92, GOST 351000.3-96 and 51000.4 -96).

To evaluate the morphologic changes in the destruction zone, laser irradiation of healthy tissue of the study animals was performed in analogy to the curettage of periodontal pockets. All animals were divided into 4 study groups. Two lasers were used for the work: the Nd:YAG laser "SMART FILE" DEKA (Italy) with a wavelength of $1064 \mathrm{~nm}$ and the KTPNd:YAG laser "SMART LITE C" DEKA (Italy) with a wavelength of $532 \mathrm{~nm}$. Before surgery, all animals were weighed, and the number of drugs administered was calculated. Premedication and anesthesia were performed with a combination of Rometar ( $3 \mathrm{mg} / \mathrm{kg}$ animal weight) and Zoletil (5 mg/kg animal weight), which was sufficient for surgery. The drugs were applied once, intramuscularly, in an experimental operating room following the rules of asepsis and antisepsis.

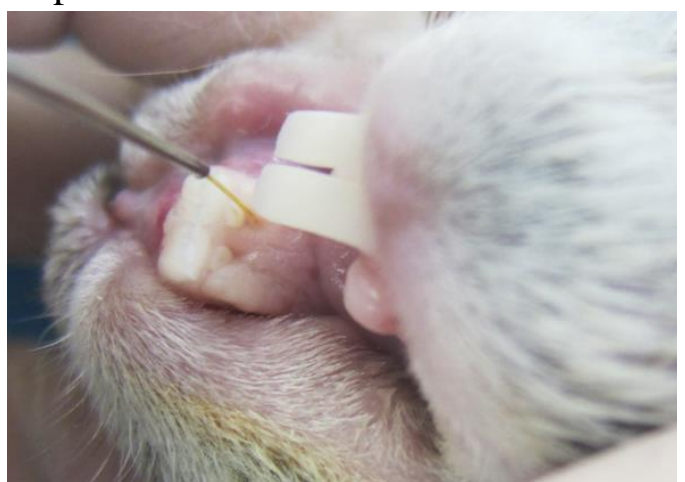

(a)

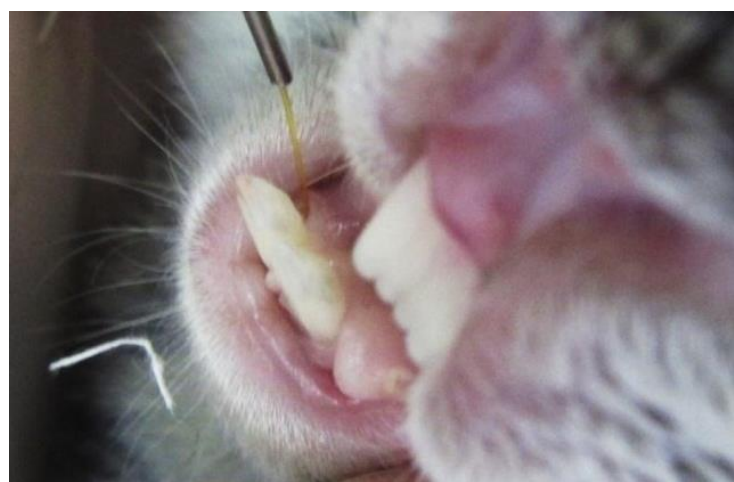

(b)

Figure 1. (a) The exposure to the $1 \mathrm{~W}$ Nd: YAG laser radiation in the upper jaw, from the palatal side, in the area of the epithelial attachment of the left incisor; (b) The exposure to radiation of the KTP-Nd:YAG laser with a power of $2 \mathrm{~W}$ in the lower jaw, from the lingual side, in the area of the epithelial attachment of the right incisor. 
In animals of the 1st group, a wound area was formed in the maxilla in the region of the epithelial attachment between the surface of the left incisor on the palatal side and the adjacent free margin of the gingiva, analogous to the curettage of periodontal pockets (Figure 1 (a), using the Nd:YAG laser with an energy of $40 \mathrm{MJ}$, a pulse duration of $350 \mathrm{~ns}$, a frequency of $25 \mathrm{~Hz}$, a power of $1.0 \mathrm{~W}$, and an exposure time of 3 seconds.

In experimental animals of the 2nd group, a wound area was formed in the maxilla, on the opposite side, in the region of the epithelial attachment of the right incisor on the palatal side and the adjacent free edge of the gingiva, using the Nd:YAG laser with an energy of 50 MJ, a pulse duration of $350 \mathrm{~ns}$, a frequency of $40 \mathrm{~Hz}$, a power of $2.0 \mathrm{~W}$, and an exposure time of 3 seconds.

In the mandible of the animals of the 3rd group, a wound area was created in the region of the epithelial attachment between the surface of the left incisor on the lingual side and the adjacent free edge of the gingiva in analogy to the curettage of periodontal pockets with the KTP-Nd:YAG laser in repetitive pulse mode, with a pulse duration of $10 \mathrm{~ms}$, with a power of $1.0 \mathrm{~W}$ and an exposure time of 3 seconds.

On the opposite side, in animals of the 4th group, a wound area was formed in the area of the epithelial attachment of the right lower incisor on the lingual side (Figure 1(b)) using a KTP-Nd:YAG laser with a pulse duration of $10 \mathrm{~ms}$, a power of $2.0 \mathrm{~W}$, in a repetitive pulse mode and with an exposure time of 3 seconds.

Table 1. Distribution of laboratory animals (rabbits) in the experiment

\begin{tabular}{c|c|c|c|c|c}
\multirow{2}{*}{$\begin{array}{c}\text { The day the ani- } \\
\text { mals were removed } \\
\text { from the experi- } \\
\text { ment }\end{array}$} & $\begin{array}{c}\text { Group 1 } \\
\text { Nd:YAG }\end{array}$ & $\begin{array}{c}\text { Group 2 } \\
\text { Nd:YAG }\end{array}$ & $\begin{array}{c}\text { Group 3 } \\
\text { KTP - } \\
\text { Nd:YAG }\end{array}$ & $\begin{array}{c}\text { Group 4 KTP- } \\
\text { Nd:YAG }\end{array}$ & \multirow{2}{*}{ Animals (n) } \\
\cline { 2 - 5 } 1-st day & 5 & 5 & 5 & 5 & 5 \\
\hline 3-rd day & 5 & 5 & 5 & 5 & 5 \\
\hline 7-th day & 5 & 5 & 5 & 5 & 5 \\
\hline 14-th day & 5 & 5 & 5 & 5 & 5 \\
\hline $\begin{array}{c}\text { Biopsy materials } \\
\text { (n) }\end{array}$ & \multicolumn{5}{|l}{}
\end{tabular}

The animals were removed from the experiment on the 1st, 3rd, 7th, and 14th days by administering an excessive dose of zolazepam $\mathrm{HCl}$ (Zoletil®, Virbac, Carros, France) in compliance with the euthanasia rules (Table 1). The teeth (incisors of the maxilla and mandible) together with the parts of the bone tissue below the level of the neck region were sawn out by $6-7 \mathrm{~mm}$. Then they were fixed with sutures on strips of photographic paper, which was marked depending on the parameters of the laser and the exposure time. The prepared tissue sample was kept in neutral $10 \%$ formalin and sent for histological examination.

\section{Results and Discussion}

\subsection{The morphological assessment of soft tissue regeneration in experimental animals in} dynamics.

Exposure to Nd:YAG and KTP-Nd:YAG lasers on day 1 revealed a stereotypic histological picture of dystrophic changes in the gingival mucosa at the border with the tooth. 
It consisted in vaporization of intercellular and intracellular fluid of epithelial cells and submucosal layer with the formation of sterile thermal coagulation scab, blood coagulation in the lumen of arterial and venous vessels with the formation of so-called "trombi from a coagulation mode of laser " ensuring complete hemostasis. The histological picture on day 1 in all study groups differed only in the extent of the damage. The largest volume of thermal damage of the tissues of the mucosa of keratinized gum around adjacent teeth was observed in experimental animals of the 4th group, where $\mathrm{Nd}$ : YAG laser radiation with a power of $2 \mathrm{~W}$ was used (Figure 2a); the smallest volume of coagulation thermonecrosis was observed under the influence of the KTP-Nd:YAG laser with a power of $1 \mathrm{~W}$ in animals of the 1 st group (Figure $2 b)$.

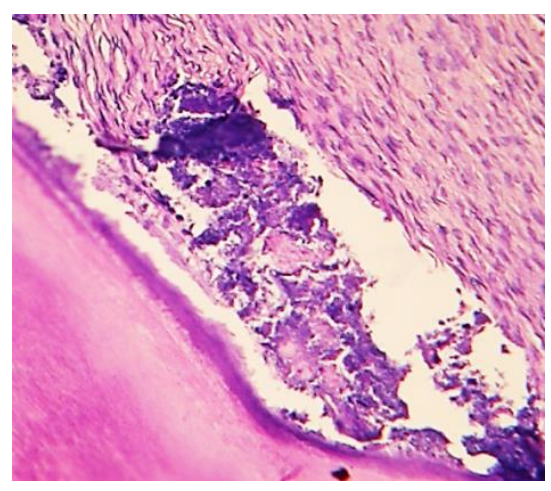

(a)

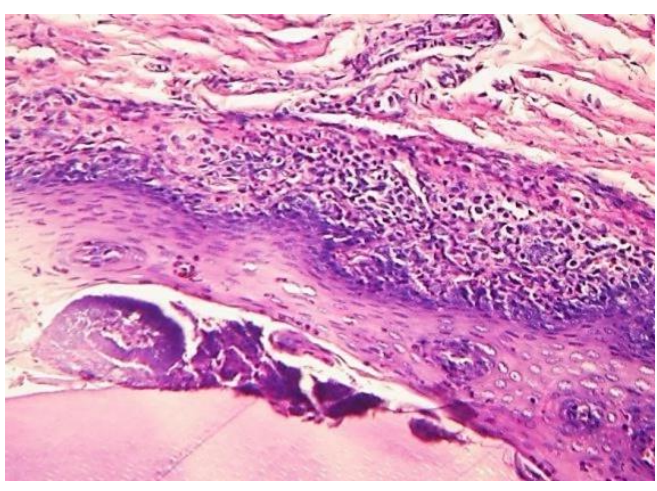

(b)

Figure 2. Coagulative thermal necrosis of the epithelium and tissues of the submucosal layer at the gingivaltooth interface on day 1: (a) after exposure to a Nd: YAG laser with a power of $2 \mathrm{~W}$ (surrounding hem.-eos. magnification x120); (b) after exposure to a KTP Nd: YAG laser with a power of $1 \mathrm{~W}$ (surrounding hem.-eos. magnification $\mathrm{x} 120)$.

In 3 days after the removal of rabbits from the experiment, in the area of laser exposure, there was a decrease in the volume of thermal coagulation necrosis, partial rejection of the coagulated tissue with the clearing of the wound channel. Between the epithelium and the submucosal layer of the gum, there were numerous cellular elements of the macrophage series, plethora, and edema of the stroma of the mucosa.

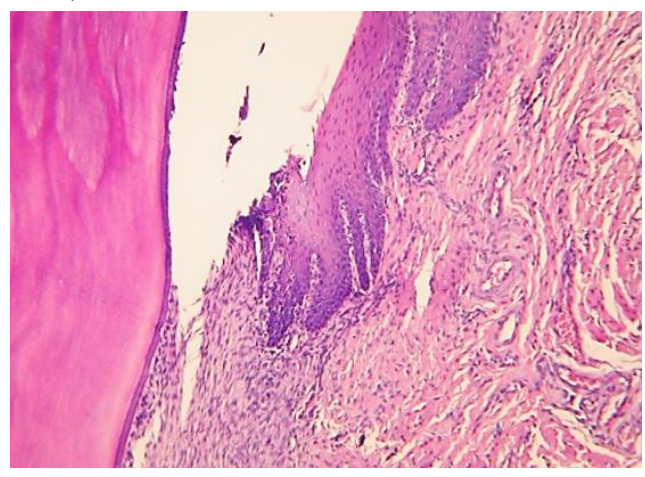

(a)

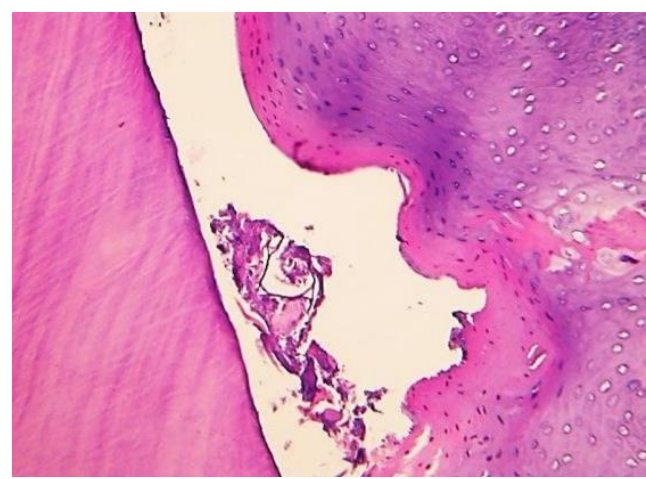

(b)

Figure 3. Fragments of a coagulation scab in the space between the mucosa of gum and surface of the teeth on day 3: (a) after irradiation with a KTP-Nd:YAG laser with a power of $1 \mathrm{~W}$ (env. gem.-eos. magnification x100);

(b) after irradiation with $2 \mathrm{~W} \mathrm{Nd}$ :YAG laser. (env. gem.-eos. magnification x100).

On the 3rd day, in the animals of the 1st group, with the use of a $1 \mathrm{~W}$ Nd:YAG laser, and in the animals of the 3rd group, after irradiation with the KTP-Nd:YAG laser, almost 
complete clearing of scab fragments in the surface areas of the epithelium of the mucosa was observed; in the submucosal layer foci of formation of granulation tissue and a pronounced venous plethora were visible (Figure 3a). In groups 2 and 4, in experimental animals irradiated with $2 \mathrm{~W}$ Nd:YAG and KTP-Nd:YAG lasers, there were scab fragments in the space between the mucosa of gum and the surface of the teeth (Figure $3 \mathrm{~b}$ ). The histological picture after irradiation with Nd:YAG and KTP-Nd:YAG lasers was similar and differed only in the extent of damage at different power parameters, characterized by the formation of granulation tissue with numerous newly formed capillaries, cellular elements of the macrophage series, and the absence of neutrophil infiltration.

On day 7, in experimental animals of the 1st and 3rd groups, after irradiation with Nd:YAG and KTP-Nd:YAG lasers with a power of $1 \mathrm{~W}$, the histological structure of the stratified squamous epithelium and the submucosal layer between the tooth and the gingiva was almost completely restored. In the 2nd and 4th groups, after exposure to the Nd:YAG and KTP-Nd:YAG lasers with a power of $2 \mathrm{~W}$, the epithelial coverage of the gingival mucosa were restored in the animals, but there was venous congestion and the formation of granulation tissue with numerous newly formed capillaries and cellular elements of the macrophage series with a small number of neutrophils. In the space between the tooth and the gingiva, there were a few monocytes, eosinophils, neutrophils, and the coagulation scab fragments were absent in all study groups (Figure 4a).

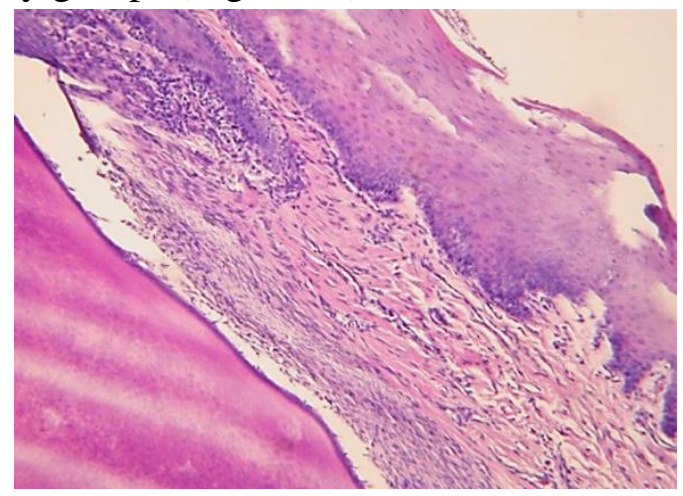

(a)

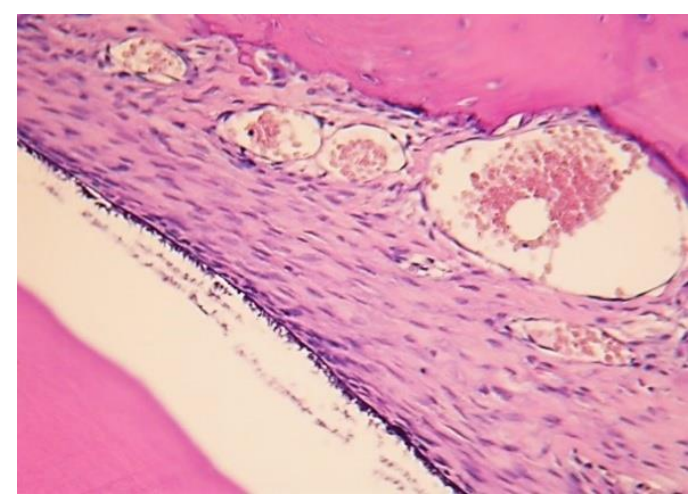

(b)

Figure 4. (a) Regeneration of the stratified squamous epithelium of the gingiva, maturation of the granulation tissue of the submucosal layer with the restoration of its structure on the 7th day after exposure $1 \mathrm{~W}$ Nd:YAG laser irradiation. (Surrounding gem. -eos. magnification x100); (b) Complete recovery of the histological structure of the stratified squamous epithelium on the 14th day after exposure to $2 \mathrm{~W}$ Nd:YAG laser irradiation. (Surrounding gem. -eos. Magnification. x100).

On day 14, after irradiation with both the Nd:YAG laser and the KTP-Nd:YAG laser, the anatomical and histological structure of the gingiva in the area of the epithelial attachment between the tooth and the free gingiva, where laser exposure occurred, was completely restored in the animals of all 4 groups.

The Nd:YAG laser is a free-running pulsed wave laser with a wavelength of $1064 \mathrm{~nm}$. Unlike carbon dioxide and erbium lasers, the neodymium laser has a low absorption coefficient in water, and its energy is either scattered or penetrates living tissue. Due to its penetration and thermogenesis properties, the Nd:YAG laser forms a relatively thick coagulation layer on the soft tissue surface and thus exhibits good hemostasis. Consequently, the Nd:YAG laser effectively removes soft tissues with a high risk of bleeding. Many researchers worldwide have studied the effect of neodymium laser radiation on hard and soft tissues and the optimal 
protocols for working with them [15-17]. Summarizing all the studies on the treatment of periodontal diseases, we can see that opinions on using the Nd:YAG laser differ. For example, the American Academy of Periodontology does not recommend the use of laser curettage with Nd:YAG, while the Academy of Laser Dentistry (ALD) claims the need for laser use as an additional method for curettage after conventional mechanical root canal treatment. Based on the results of in vitro and in vivo studies, the Nd: YAG laser should not reach the root surface because it is unable to remove plaque adequately but can alter the root surface, generating heat during irradiation. When used, the Nd:YAG laser should be used as an adjunct to conventional mechanical treatments and not as a primary tool in treating periodontal pockets [18-20].

The Nd:YAG laser can cure periodontal pockets, remove infected granulation tissue, and disinfection. Several clinical studies that used Nd:YAG laser as the sole treatment method for periodontal pockets failed to demonstrate sufficiently good clinical results compared with conventional mechanical treatment. In these studies, plaque removal was inadequate, and the inevitable excessive thermal stress of the laser was noted. During the course of the study, the authors obtained variable results depending on the degree of irrigation of the surgical field, the angle of inclination of the tip, and other factors.

In 2013, S.V. Tarasenko et al. presented the results of treatment of 93 patients with vascular formations in the maxillofacial region: of these, 73 patients were treated with a laser, and 20 patients underwent traditional surgical excision and sclerotherapy. A Nd:YAG laser (with a wavelength of $1064 \mathrm{~nm}$ ) and a diode laser (with a wavelength of $0.98 \mu \mathrm{m}$ ) were used for laser treatment. The devices were used in a repetitively pulsed mode of operation and with an average radiation power of $2-5 \mathrm{~W}$. We used to contact (interstitial), noncontact, and combined techniques. Ultrasound was used for primary diagnosis and dynamic control of vascular lesions. According to clinical studies, similar results were obtained after using diode and Nd:YAG lasers. On the 7th day after surgery, there was a decrease in vessel formation to $60-70 \%$ of the original volume, their compaction. All patients showed decreased pain intensity and decreased postoperative edema compared to the traditional surgical method and hardening. The scar that formed after laser irradiation was barely noticeable. The use of these treatment methods reduced the trauma of treatment of patients with vascular formations in the maxillofacial region, which, according to the authors, allowed a good esthetic result in all cases and significantly improved the quality of treatment of vascular formations.

\section{Conclusions}

The mechanisms of action of Nd:YAG laser radiation and KTP-Nd:YAG laser are similar, and the amount of thermal damage depends only on the power density of the laser radiation. As a result of the obtained studies, both dental lasers can be used for the surgical treatment of inflammatory periodontal diseases, with the correction of the ablation mode towards a power reduction from $2 \mathrm{~W}$ to $1 \mathrm{~W}$.

The use of high-energy laser radiation in the surgical treatment of inflammatory periodontal diseases allows a significant reduction in trauma to the tissues of the surgical area, a reduction in operating time due to improved visualization as a result of good hemostasis and selective action on pathologic tissues, and a reduction in the risk of pus complications due to bactericidal action. This ensures the aseptic, productive nature of the inflammatory reaction, the early formation of granulation tissue and thus shortens the treatment time. 


\section{Funding}

This research received no external funding.

\section{Conflicts of Interest}

The authors declare no conflict of interest.

\section{Acknowledgments}

\section{We express our gratitude to our University for the opportunity to conduct research work.}

\section{References}

1. Lione, R.; Pavoni, C.; Noviello, A.; Clementini, M.; Danesi, C.; Cozza, P. Conventional versus laser gingivectomy in the management of gingival enlargement during orthodontic treatment: a randomized controlled trial. Eur. J. Orthod. 2020, 42, 78-85, https://doi.org/10.1093/ejo/cjz032.

2. Gadzhula, N.G.; Shinkaruk-Dykovytska, M.M.; Cherepakha, O.L.; Goray, M.A.; Horlenko, I.M. Efficiency of using the diode laser in the treatment of periodontal inflammatory diseases. Wiad. Lek. 2020, 73, 841-845.

3. Ahn, J.H.; Power, S.; Thickett, E. Application of the diode laser for soft-tissue surgery in orthodontics: Case series. J. Orthod. 2021, 48, 82-87, https://doi.org/10.1177/1465312520958706.

4. Wu, Y.Z.; Zhou, Y.; Mei, Y.M.; Huan, H.; Sun, J.W. [Clinical evaluation of Er:YAG laser in the treatment of grade II periodontitis with bifurcation lesions]. Shanghai kou qiang yi xue = Shanghai journal of stomatology 2020, 29, 308-311.

5. Roy, M.; Loutan, L.; Garavaglia, G.; Hashim, D. Removal of osseointegrated dental implants: a systematic review of explantation techniques. Clin. Oral Investig. 2020, 24, 47-60, https://doi.org/10.1007/s00784-01903127-0.

6. de Jesus, A.O.; Matias, M.D.P.; de Arruda, J.A.A.; Aires, A.V.; Gomes, I.P.; Souza, L.N.; Abreu, L.G.; Mesquita, R.A. Diode laser surgery versus electrocautery in the treatment of inflammatory fibrous hyperplasia: a randomized double-blind clinical trial. Clin. Oral Investig. 2020, 24, 4325-4334, https://doi.org/10.1007/s00784-020-03296-3.

7. Lobato, R.P.B.; Kinalski, M.d.A.; Martins, T.M.; Agostini, B.A.; Bergoli, C.D.; dos Santos, M.B.F. Influence of low-level laser therapy on implant stability in implants placed in fresh extraction sockets: A randomized clinical trial. Clin. Implant Dent. Relat. Res. 2020, 22, 261-269, https://doi.org/10.1111/cid.12904.

8. Sezen, D.; Hatipoğlu, M.; Üstün, K. Evaluation of the clinical and biochemical efficacy of erbium, chromium:ytrium-scandium-gallium-garnet (ER,CR:YSGG) laser treatment in periodontitis. Lasers Med. Sci. 2020, 35, 1567-1575, https://doi.org/10.1007/s10103-020-02990-8.

9. Wang, C.-W.; Ashnagar, S.; Gianfilippo, R.D.; Arnett, M.; Kinney, J.; Wang, H.-L. Laser-assisted regenerative surgical therapy for peri-implantitis: A randomized controlled clinical trial. J. Periodontol. 2021, 92, 378-388, https://doi.org/10.1002/JPER.20-0040.

10. Sfasciotti, G.L.; Zara, F.; Vozza, I.; Carocci, V.; Ierardo, G.; Polimeni, A. Diode versus CO2 Laser Therapy in the Treatment of High Labial Frenulum Attachment: A Pilot Randomized, Double-Blinded Clinical Trial. Int. J. Env. Res. Public Health 2020, 17, https://doi.org/10.3390/ijerph17217708.

11. Laky, M.; Laky, B.; Arslan, M.; Lettner, S.; Müller, M.; Haririan, H.; Husejnagic, S.; Rausch-Fan, X.; Wimmer, G.; Moritz, A.; Gregor, R. Effectiveness of a 655 -nm InGaAsP diode laser to detect subgingival calculus in patients with periodontal disease. J. Periodontol. 2021, 92, 547-552, https://doi.org/10.1002/JPER.190663 .

12. Larionova, E.; Diachkova, E.; Morozova, E.; Davtyan, A.; Tarasenko, S. Laser-assisted tooth extraction in patients with impaired hemostasis. Biomedicine 2021, 11, 47-54, https://doi.org/10.37796/2211-8039.1072.

13. Ghodke, P.S.; Hegde, R.; Ansari, W.; Muglikar, S.; Dholkawala, A.S. A Study to Evaluate the Efficacy of an 810-nm Diode Laser in the Maintenance of Dental Implants: A Peri-Implant Sulcular Fluid Analysis. J. Oral Implantol. 2020, 46, 381-388, https://doi.org/10.1563/aaid-joi-D-19-00104.

14. Rückschloß, T.; Ristow, O.; Kühle, R.; Weichel, F.; Roser, C.; Aurin, K.; Engel, M.; Hoffmann, J.; Freudlsperger, C. Accuracy of laser-melted patient-specific implants in genioplasty - A three-dimensional 
retrospective study. Journal of Cranio-Maxillofacial Surgery 2020, 48, 653-660, https://doi.org/10.1016/j.jcms.2020.05.003.

15. Civak, T.; Ustun, T.; Yilmaz, H.N.; Gursoy, B. Postoperative evaluation of Er:YAG laser, piezosurgery, and rotary systems used for osteotomy in mandibular third-molar extractions. Journal of Cranio-Maxillofacial Surgery 2021, 49, 64-69, https://doi.org/10.1016/j.jcms.2020.11.010.

16. Liu, J.; Zhou, Z.; Zhang, S. Effects of Er:YAG Laser on the Attachment of Human Periodontal Ligament Fibroblasts to Denuded Root Surfaces Simulating Delayed Replantation Cases: An In Vitro Study. Photobiomodulation, Photomedicine, and Laser Surgery 2019, 38, 145-150, https://doi.org/10.1089/photob.2019.4699.

17. Tarasenko, S.; Stepanov, M.; Morozova, E.; Unkovskiy, A. High-level laser therapy versus scalpel surgery in the treatment of oral lichen planus: a randomized control trial. Clin. Oral Investig. 2021, https://doi.org/10.1007/s00784-021-03867-y.

18. Tarasenko, S.V.; Repina, S.I.; Garipov, R.D.; Morozova, E.A. Influence of Laser Irradiation to the Structure of Dental Implant Surface during Professional Oral Hygiene. In Proceedings of 2020 International Conference Laser Optics (ICLO), 2-6 Nov. 2020, https://doi.org/10.1109/iclo48556.2020.9285927.

19. Kharalampos, M.; Put, V.A.; Tarasenko, S.V.; Reshetov, I.V. Comprehensive patient rehabilitation while performing immediate dental implant placement with the use of information-wave therapy (literature overview). J. Adv. Pharm. Educ. Res 2020, 10, 11-14.

20. Grzech-Leśniak, K.; Belvin, B.R.; Lewis, J.P.; Golob Deeb, J. Treatment with Nd:YAG Laser Irradiation Combined with Sodium Hypochlorite or Hydrogen Peroxide Irrigation on Periodontal Pathogens: An In Vitro Study. Photobiomodulation, Photomedicine, and Laser Surgery 2020, 39, 46-52, https://doi.org/10.1089/photob.2019.4775. 